\title{
Empirical Research on Urban and Rural Education Equality of Inner Mongolia Under the Background of Urban-rural Integration-Analysis Based on Education Gini Coefficient
}

\author{
Linlin Liu ${ }^{1}$, Jinpeng $\mathrm{Wei}^{2}$ and $\mathrm{Na}$ Zhang ${ }^{3}$ \\ \{liulinlin@imu.edu.cn'1,weijinpeng0202@163.com²,2605267865@qq.com³
}

School of Marxism Inner Mongolia University ${ }^{1}$, School of Public Management Inner Mongolia University $^{1}$, School of Public Management Inner Mongolia University ${ }^{23}$, School of Public Management Inner Mongolia University ${ }^{23}$

\begin{abstract}
This paper selects the statistical data of education situation in Inner Mongolia from 2002 to 2018, and analyzes the changes of educational equity in Inner Mongolia by using the decomposition method of education Gini coefficient. The results show that the education level of the population is increasing, the Gini coefficient of education is decreasing, and the overall education equity has achieved remarkable results, which is in a overall fair stage; the gap between urban and rural education years has increased, and the contribution rate of urban and rural education difference has been maintaining at a rather high figure and shows the trend of continuous increase. It can be seen that the difference between urban and rural education is the main cause of restricting the development of educational equity in Inner Mongolia, and will exist for a certain period of time. The restrictive factors that cause the gap between urban and rural education equity are mainly reflected in the imbalance of the economic social structure, the imperfection of government responsibility and public investment system, the dilution of educational resources by educational immigrants, and the low level of protection of rural teachers' professional rights and interests. Promoting the integration of urban-rural compulsory education is the fundamental way to narrow the gap between urban and rural areas and solve the problems of rural education development. Specifically speaking, we should build a multi governance community of urban and
\end{abstract}

\footnotetext{
1 Author: Linlin Liu (1981 ), female, doctoral candidate, School of Marxism, Inner Mongolia University. Jinpeng Wei (1996 ), male, master of School of public administration, Inner Mongolia University. Zhang Na (1996 ), female, graduate student, School of public administration, Inner Mongolia University.

Fund Project: scientific research project of colleges and universities in Inner Mongolia Autonomous Region "Research on high quality and balanced development path of compulsory education in Inner Mongolia under the background of urban-rural integration" (NJSY21287).
} 
rural education led by the government, in order to promote the two-way flow of urban and rural education resources, continue to implement the rural-teacher-support plan, vigorously develop rural preschool education, promote education targeted poverty reduction, and promote education equity through education informatization.

Keywords: Ethnic minority areas; education equality; urban-rural integration; education Gini coefficient.

\section{Introduction}

The Fifth Plenum of the 19th Central Committee of the Communist Party of China has clearly stated that by the time of 2035, we will achieve the goal of building a education power, reaching a new high level with national qualities and social civilization, achieving new actual developments of the human development in every aspects and common prosperity. Standing at a new historical starting point, developing more fair and quality education is an inevitable choice to adapt to the changes of in the principle social contradictions and the characteristics of high-quality development stage. It's also an inevitable choice to improve the level of education modernization and meet the ever-growing needs for a better life. Achieve these great aims and "Not a target shall be neglected" "Not a single region or nation shall be left behind". In recent years, the issue of educational equity has draw the attention of domestic scholars. In empirical studies, standard deviation and Gini coefficient are used to measure the degree of educational inequity, and most of the studies prefer Gini coefficient method. Changzheng Chang, Zhijian Xun, Huaizu Li and Baicai Sun has calculated the education Gini coefficient of China over the years. The results show that the total number of years of education of our population is increasing year by year, the Gini coefficient of education is decreasing year by year, and the degree of education equity has been greatly improved, but there is still a long way to go compared with the world level. [1],[2],[3] Dexin $\mathrm{Hu}$ analyzed the education development level and education equity of cities, counties and townships in China.[4] Wanming Zhang used education Gini coefficient, and analyzed the overall education equity and inter provincial education equity from the perspective of education outcome equity. She holds that the overall education equity is improved, while the inter provincial education development is seriously unfair.[5] Zhenhua $\mathrm{Wu}$ calculated and analyzed the level and trend of educational equity of rural residents in China between and within provinces. We can tell from his research that Inner Mongolia is an area with strong willingness to receive education and of general public education resources.[6] Based on the trend of education years, education Gini 
coefficient of urban and rural population in Inner Mongolia, and the gap between urban and rural education years by gender and by rural or urban areas, this paper expounds the degree of education equity in Inner Mongolia, the main causes and constraints of education injustice at this stage, and puts forward countermeasures and suggestions.

\section{Method AND SUMMARY STATISTICS}

\subsection{Method}

When it comes to the measurement of educational equity, we usually measure the degree of difference and equilibrium through educational development indicators, such as Gini coefficient, difference coefficient, equilibrium index and so on. And education Gini coefficient is widely used by scholars because of its stability and effectiveness. This paper also applied the education Gini coefficient measurement method to decompose the overall equity of Inner Mongolia's education development according to the differences among cities, counties and townships, and thus analyze the contribution of urban-rural gap to the overall education equity, and evaluate the urban-rural equity of Inner Mongolia's education development trend.At the same time, considering the differences of gender equity between urban and rural areas, we also decomposes the gender education equity among cities, counties and townships.

\subsubsection{Measurement of educational equity}

The measurement of education Gini coefficient is derived from the calculation principle of Gini coefficient. According to the Gini coefficient: when Gini coefficient is lower than 0.2, it means absolute fairness, $0.2 \sim 0.3$ means relatively fair, $0.3 \sim 0.4$ means relatively reasonable, $0.4 \sim 0.5$ means the gap is relatively large, and 0.5 above means a wide gap, and 0.4 is usually used as the "warning line" of Gini coefficient's evaluation. This standard is also applicable to the education Gini coefficient of education, that is, the higher the education Gini coefficient of education, the lower the degree of education equity. The calculation formula is as follows:

$$
\mathrm{G}=1-\sum_{\mathrm{i}=1}^{5}\left(\mathrm{X}_{\mathrm{i}}-\mathrm{X}_{\mathrm{i}-1}\right)\left(\mathrm{Y}_{\mathrm{i}}+\mathrm{Y}_{\mathrm{i}-1}\right)
$$

As we can see in equation (1), where $G$ is the education Gini coefficient, $i$ is the level of 
education, $\mathrm{x}_{\mathrm{i}}$ is the cumulative proportion of the educated population at each level in the total population, $\mathrm{y}_{\mathrm{i}}$ is the cumulative proportion of the number of years of education of the population at each level in the total number of years of Education,[7] and 5 is the classification of the number of education levels. According to the current school year system and education system of our country, and from the research of other scholars, the education level can be divided into five levels: the first level, no schooling, and its years of education is 0 ; the second level, primary school, and its years of education is 6; the third level, junior high school, and its years of education is 9 ; the fourth level, senior high school or technical secondary school, and its years of education is 12; The fifth level is junior college or above, with 16 years of education.

\subsubsection{Decomposition of Education Gini coefficient}

In order to analyze the contribution of each factor to Gini coefficient, we need to further decompose the composition of Gini coefficient. At present, there are mainly two methods to decompose Gini coefficient : one is the trichotomy method, that is, to decompose Gini coefficient into intra-group, inter-group and residual items, represented by the decomposition formula of Yao (1999), [8] and Hangkong Zhang (2013)[9] and others have conducted relevant research based on this method. The decomposition formula of Gini coefficient of education is as follows:

$$
\mathrm{G}=\mathrm{G}_{\mathrm{a}}+\mathrm{G}_{b}+\mathrm{G}_{\mathrm{c}}
$$

As we can see in equation (2), where $G_{a}$ is the internal components due to the difference of educational level within groups. $\mathrm{G}_{\mathrm{b}}$ is the components between groups due to the difference of educational level among groups.$G_{c}$ refers to the remaining part or the overlapping part of groups to reflect the differences among groups.

The other is dichotomy, which is to divided samples into intra-group and inter-group, represented by the decomposition formula of Junsen Zhang (2002)[10], and Baicai Sun(2014) and others conducted relevant research based on this method. In view of the fact that the remaining items in the first method overlap with intra-group and inter-group, which will weaken the accuracy of inter-group and intra-group's contribution. Thus we chose the second method to decompose the education Gini coefficient. The specific decomposition formula is as follows: 


$$
\mathrm{G}=\sum_{\mathrm{i}=1}^{\mathrm{n}} P_{\mathrm{i}}^{2} \cdot\left(\frac{\mu_{i}}{\mu}\right)^{2} \cdot G_{i}+G_{B}
$$

As we can see in equation (3), where $G$ is the education Gini coefficient ; $P_{i}$ is the proportion of group i's population; $\mu_{i}$ and $\mu$ represent the average years of education of group $i$ and total population's average years of education respectively; $\mathrm{G}_{\mathrm{i}}$ represents the education Gini coefficient of each group, $P_{i}{ }^{2} \cdot\left(\frac{\mu_{i}}{\mu}\right)^{2} \cdot G_{i}$ is the absolute contribution of intra-group gap to the overall education Gini coefficient, and in the following parts we will refer it as $\mathrm{R}_{\mathrm{i}}$; $\mathrm{G}_{\mathrm{b}}$ is the absolute contribution of inter-group gap to the overall education Gini coefficient.[11] The relative contribution of each part and the relationship between them are as follows:

$$
\sum_{i=1}^{n} \frac{R_{i}}{G} \times 100 \%+\frac{R_{B}}{G} \times 100 \%=1
$$

\subsection{Data}

"China Population \& Employment Statistic Yearbook" has counted the population of cities, counties and townships of all provinces, autonomous regions and cities in China by gender and education level, and the data set is authoritative and available. We selected the statistical data of the education situation of people in Inner Mongolia from 2002 to 2018, divided by city, county and country and by gender.

In 2002, the Ministry of Education issued "the notice on strengthening the management of basic education", which clearly put forward that "To actively promote the balanced development of schools in the stage of compulsory education". Since then, the development of compulsory education has begun to change to the direction of "balanced", and "key schools and key classes" have been gradually canceled. Therefore, 2002 is the key year of China's education reform and development since the reform and opening up.

\section{Analysis of research results}

\subsection{Urban-rural difference of per capita education years in Inner Mongolia}

As can be seen from Figure 1, the average number of years of education per capita in 
Inner Mongolia has increased from 7.88 years in 2002 to 9.69 years in 2018. The required number of years of compulsory education has been completed. Combined with the proportion of population grouped by education level, we can tell that the overall educational level of Inner Mongolia population is in the transition stage from junior high school to senior high school.

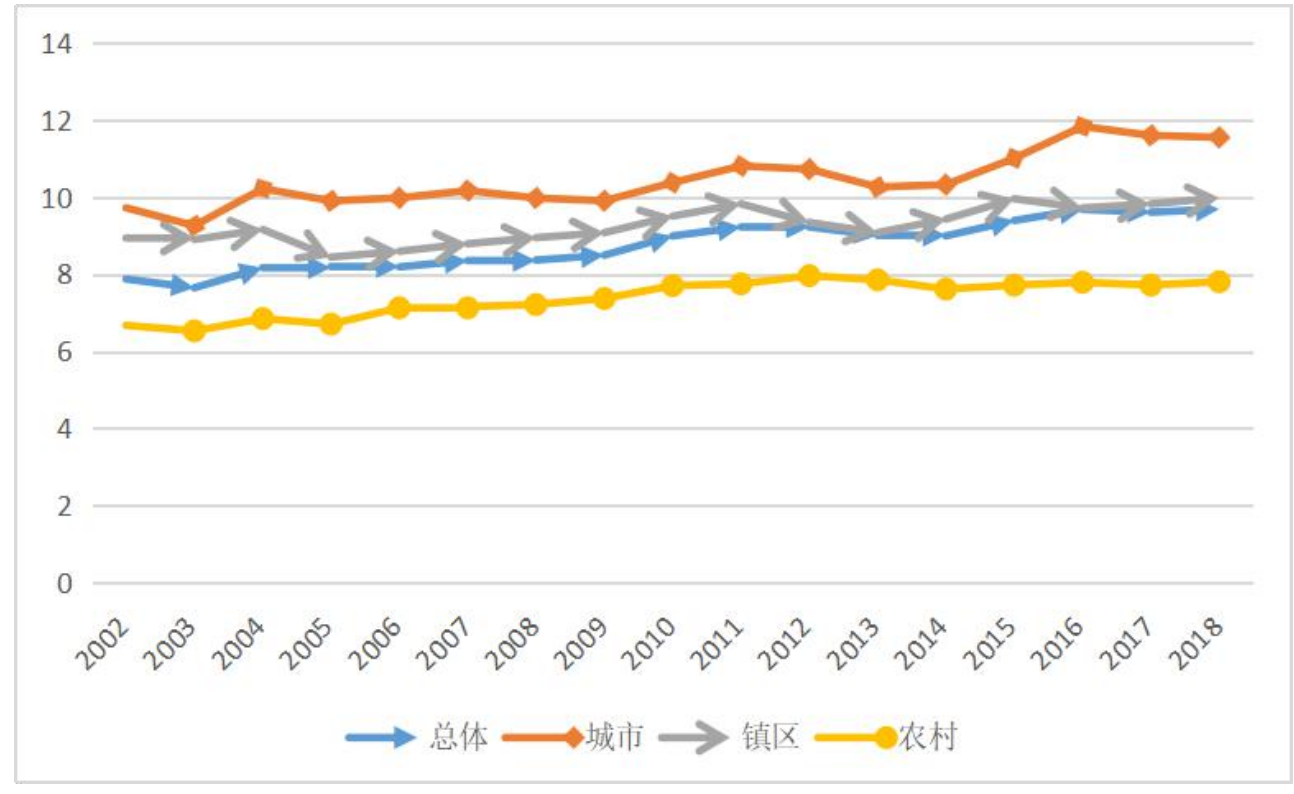

Fig. 1. Architecture of a typical wireless sensor node.

Although the gap of education opportunities between urban and rural population is gradually narrowing, and the per capita education level is steadily improving, the gap between urban and rural residents' per capita education years has expanded, and the gap is mainly reflected in the education opportunities of senior high school and above and also the illiteracy and semi illiteracy rate. In 2018, the number of years of education per capita in cities will reach 11.55 years, and more than $50 \%$ of urban residents will have access to high school and above education. Nearly one third of the population is of college education or above, which is way higher than that in towns and rural areas.

The proportion of educational population at all levels in the township is close to the overall level. The number of years of education per capita in rural areas has not yet reached the level of nine-year compulsory education; the education level of the population accounts for the vast majority of primary schools and junior high schools, and the proportion of residents receiving or has received high school education or above is only $15 \%$, but the proportion of 
uneducated population is still as high as $9.06 \%$, which is related to the migration of labor force and education derived from urbanization. In combination, the gap between the education level of rural population and the overall is still very wide. This situation will exist for a long time at present and in the future. The improvement of rural education level is still a short link restricting the development of urban-rural education integration.

Table 1. Proportion of urban and rural education population at all levels in Inner Mongolia Autonomous Region in 2018

\begin{tabular}{|c|c|c|c|c|}
\hline \multirow{2}{*}{$\begin{array}{l}\text { Education level of } \\
\text { population }\end{array}$} & \multicolumn{4}{|c|}{ Proportion } \\
\hline & Total & City & County & Township \\
\hline no schooling & $5.29 \%$ & $1.83 \%$ & $4.38 \%$ & $9.06 \%$ \\
\hline primary school & $22.96 \%$ & $11.53 \%$ & $20.16 \%$ & $35.26 \%$ \\
\hline junior high school & $35.64 \%$ & $28.15 \%$ & $37.96 \%$ & $40.73 \%$ \\
\hline $\begin{array}{l}\text { senior high school or } \\
\text { technical secondary school }\end{array}$ & $16.78 \%$ & $25.74 \%$ & $16.12 \%$ & $9.17 \%$ \\
\hline junior college or above & $19.33 \%$ & $32.75 \%$ & $21.39 \%$ & $5.78 \%$ \\
\hline
\end{tabular}

As we can see from Figure 2, from the perspective of gender differences in the number of years of education per capita, the gap between men and women in the whole and in urban and rural areas is narrowing, and the gap of years of education between men and women in 2018 is about 50\% smaller than that in 2002. Among the differences of divided groups of educational years in different genders, the average educational years of men are higher than that of women, and the educational years of urban genders are less than that of rural ones. The average number of years of education for rural women is the lowest. The reason for this trend is not only the unbalanced development of urban and rural education, but also the deep rooted influence of gender discrimination in education concept, especially in rural and pastoral areas. 


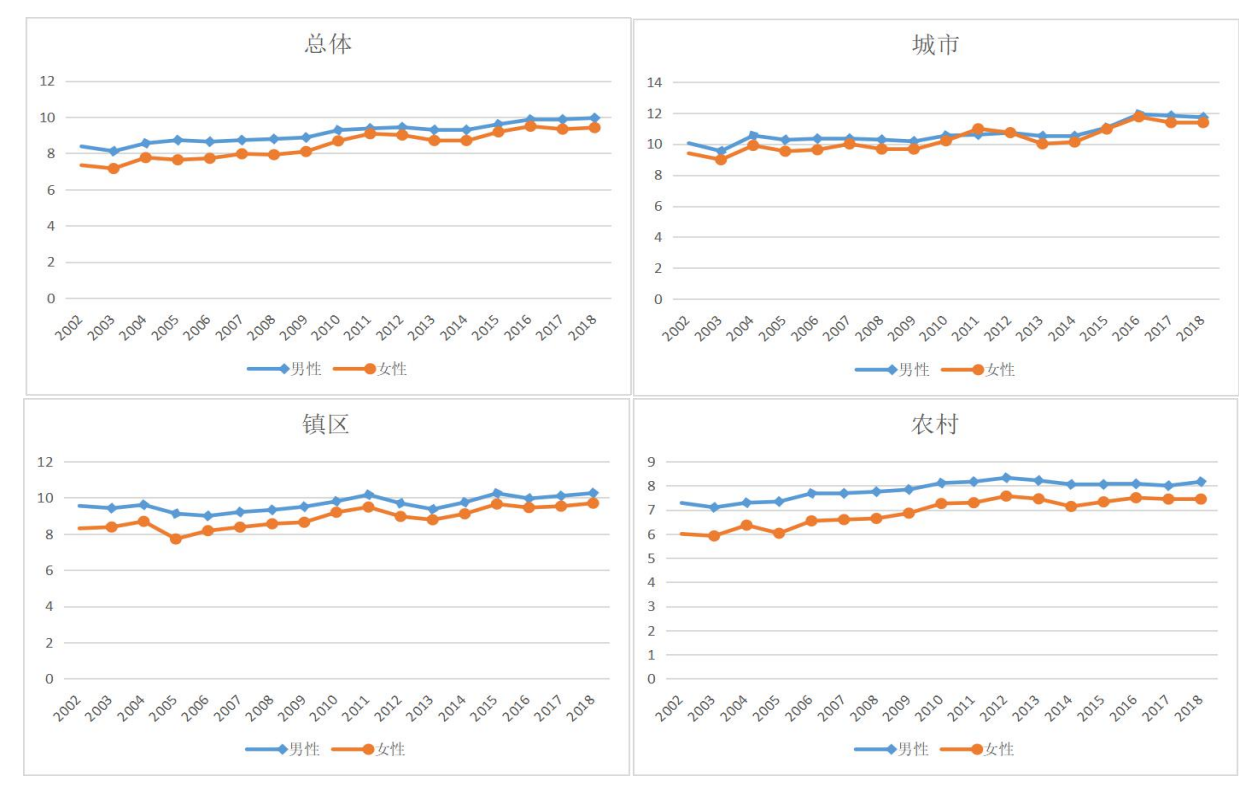

Fig. 2. Years of education for urban and rural residents in Inner Mongolia Autonomous Region

(2002-2018)

\subsection{Urban-rural differences in education Gini coefficient in Inner Mongolia}

In the context of urban-rural dual structure system, the gap between urban and rural education development is obvious, the inequality of education opportunities between urban and rural population has been criticized, and rural education has been accused of being in "poverty". In recent years, the central and local government departments at all levels have attached great importance to the balanced development of urban and rural public education, trying to narrow the education gap by rationally allocating education resources and leaning towards the rural areas, remote poverty-stricken areas and ethnic minority areas.

When it comes to the gap between urban and rural education, the society is more concerned about whether the gap is improving or worsening. As can be seen from Figure 3, the degree of education equity of urban and rural residents in Inner Mongolia has improved rapidly. With the increase of per capita schooling years, the education Gini coefficient of urban and rural shows a downward trend, from 0.262 in 2002 to 0.230 in 2018; and from 0.204, 0.228 and 0.275 in urban, township and rural areas to $0.179,0.219$ and 0.235 respectively. 


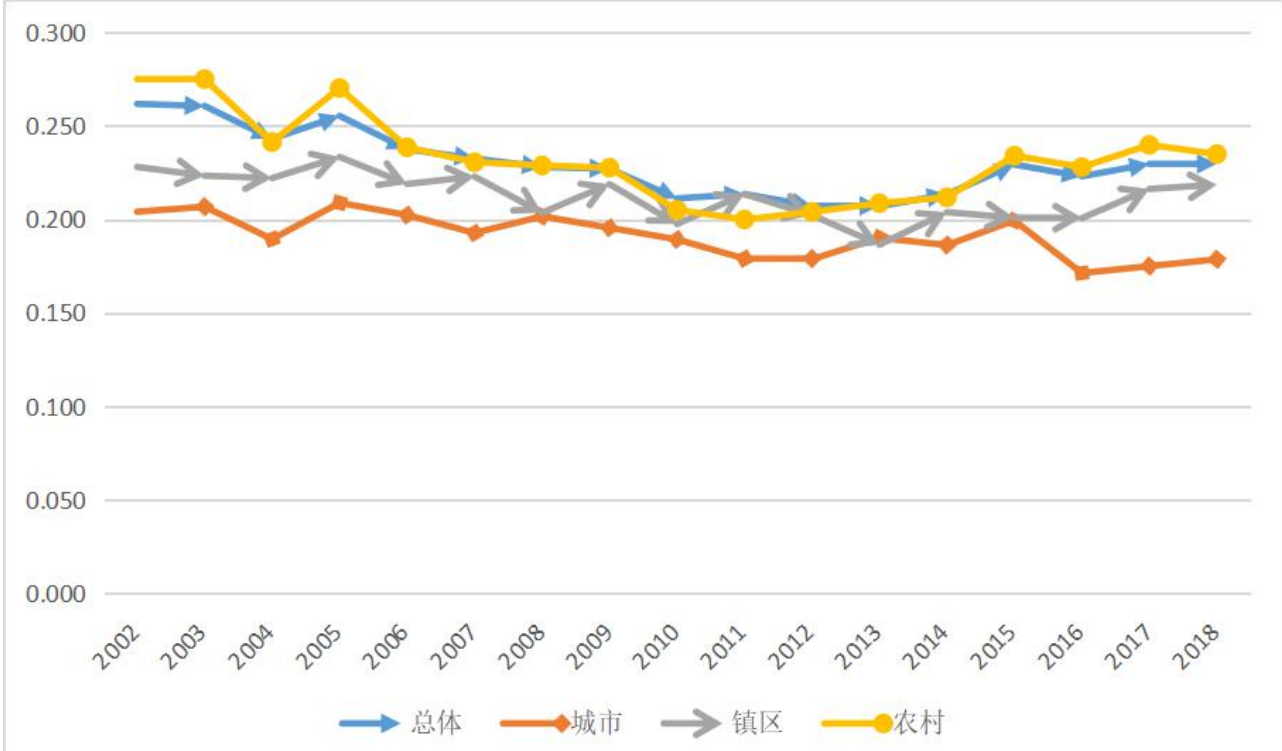

Fig. 3. Education Gini coefficient of urban and rural in Inner Mongolia Autonomous Region $(2002-2018)$

As we can see in Figure 4, from the perspective of gender between urban and rural areas, the Gini coefficient of the whole and within urban and rural areas shows a downward trend, in which the downward trend of women is higher than that of men, and the downward trend of rural areas is higher than that of urban areas. To some extent, it reflects the improvement of education equity brought by the improvement of rural education in recent years. From the perspective of gender gap, the gap of education Gini coefficient between genders is narrowing, but women is higher than men in all the groups. Among them, the Gini coefficient of rural women is the highest. Combined with the level of per capita education years, it shows that the education situation of rural women is the most unfair in urban-rural areas and gender. This also shows that while vigorously promoting the integration of urban and rural education, we should also protect the right to be educated between different genders in urban and rural areas. 


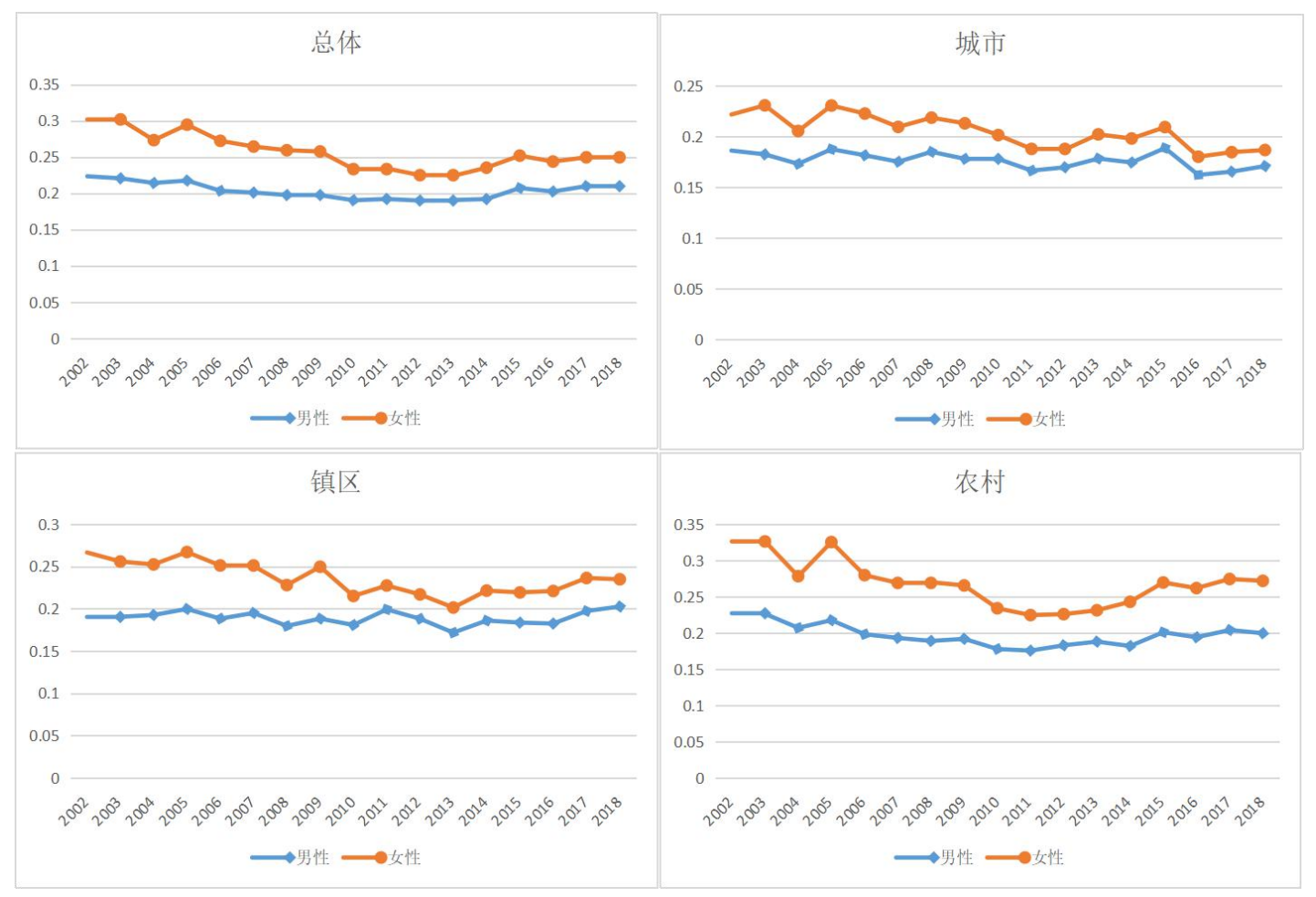

Fig. 4. Gender education Gini coefficient of urban and rural in Inner Mongolia Autonomous Region (2002-2018)

\subsection{Analysis of Education Gini coefficient of Inner Mongolia}

As we can see in Figure 5, the decomposition results of education Gini coefficient shows the following three characteristics:

First, the contribution rate of cities and towns to the unfair development of education is on the rise. The contribution rate of cities increased from $8.55 \%$ in 2002 to $13.14 \%$ in 2018 ; the contribution rate of counties increased from $3.24 \%$ to $7.51 \%$. These rising trend is mainly due to the dilution of urban education level after the rural population with lower education level flows into cities and counties, thus expanding the education inequality within cities and counties.

Second, the contribution rate of rural areas to the unfair development of education has decreased significantly. The contribution rate of rural areas decreased from $23.79 \%$ in 2002 to $9.47 \%$ in 2018 . On the one hand, it has benefited from the strong investment and support of the central and local governments to the education of rural pastoral areas; on the other hand, 
after the outflow of a large number of rural population, the education level of the remaining population was generally low and the internal difference was small.

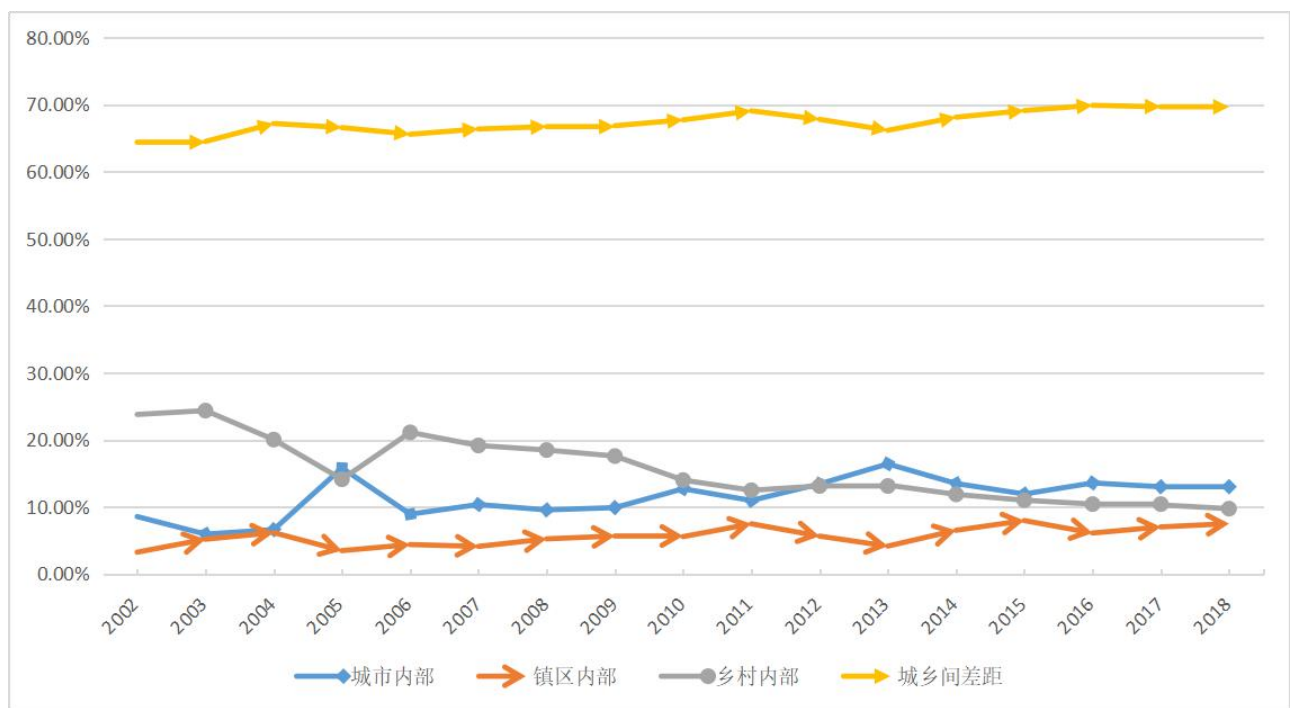

Fig. 5. Contribution of urban and rural areas to the unfair development of education in Inner Mongolia (2002-2018)

Thirdly, the contribution rate of urban-rural differences increased year by year, from $64.41 \%$ in 2002 to $69.62 \%$ in 2018 . Because the contribution rate of urban internal differences is less than that of rural internal differences, the total contribution of urban-rural internal differences to Gini coefficient gradually decreases, and the sum of the relative contribution rate of city, county and township internal differences decreases from $37.87 \%$ in 2002 to $30.39 \%$ in 2018 . This shows that the progress of educational equity mainly comes from the narrowing of the gap between urban and rural areas, especially the improvement of educational environment and the level of educational equity in rural pastoral areas. The difference between urban and rural areas has always been the main cause of the overall education inequity in Inner Mongolia, and the contribution rate to education inequity is increasing year by year.

Table 2. The contribution of education inequality between urban and rural areas

\begin{tabular}{ccccc}
\hline & $\begin{array}{c}\text { City contribution } \\
\text { rate } \\
(\%)\end{array}$ & $\begin{array}{c}\text { County } \\
\text { contribution rate } \\
(\%)\end{array}$ & $\begin{array}{c}\text { Township } \\
\text { contribution rate } \\
(\%)\end{array}$ & $\begin{array}{c}\text { Urban-rural } \\
\text { difference } \\
\text { contribution rate } \\
(\%)\end{array}$ \\
\hline 2002 & $8.55 \%$ & $3.24 \%$ & $23.79 \%$ & $64.41 \%$ \\
2003 & $5.94 \%$ & $5.18 \%$ & $24.37 \%$ & $64.52 \%$ \\
2004 & $6.61 \%$ & $6.16 \%$ & $20.04 \%$ & $67.20 \%$ \\
2005 & $15.81 \%$ & $3.47 \%$ & $14.13 \%$ & $66.59 \%$
\end{tabular}




$\begin{array}{cllll}2006 & 8.91 \% & 4.38 \% & 21.12 \% & 65.59 \% \\ 2007 & 10.35 \% & 4.10 \% & 19.16 \% & 66.38 \% \\ 2008 & 9.55 \% & 5.23 \% & 18.48 \% & 66.73 \% \\ 2009 & 9.89 \% & 5.66 \% & 17.58 \% & 66.87 \% \\ 2010 & 12.70 \% & 5.56 \% & 14.00 \% & 67.74 \% \\ 2011 & 10.96 \% & 7.48 \% & 12.48 \% & 69.09 \% \\ 2012 & 13.42 \% & 5.64 \% & 13.12 \% & 67.81 \% \\ 2013 & 16.42 \% & 4.15 \% & 13.25 \% & 66.18 \% \\ 2014 & 13.49 \% & 6.51 \% & 11.87 \% & 68.14 \% \\ 2015 & 11.92 \% & 7.96 \% & 10.99 \% & 69.12 \% \\ 2016 & 13.57 \% & 6.10 \% & 10.42 \% & 69.91 \% \\ 2017 & 13.01 \% & 7.01 \% & 10.30 \% & 69.68 \% \\ 2018 & 13.14 \% & 7.51 \% & 9.74 \% & 69.62 \% \\ 2002-2018 & 11.43 \% & 5.61 \% & 15.58 \% & 67.39 \% \\ \text { average } & & & & \end{array}$

\section{Analysis of restrictive factors}

\subsection{The economic social structure leads to the widening gap between urban and rural education}

Since the founding of the People's Republic of China, the Household Register System has been used as a method to restrain rural residents from pouring into the urban, which is closely connected to the allocation of all sorts of resources. Under the effect of the urban-rural-segregated Household Registration System, the unique "urban-rural dual structure" were formed, and the development gap between urban and rural areas exists in various fields. This makes it difficult for cities and rural areas to form a optimum interactive relationship. Among all kinds of unfairness caused by this, the unfairness of urban and rural education development has the greatest and deepest impact on the overall social development of our country, which is mainly reflected in the inequality of urban and rural education opportunities, the inequality of urban and rural education management and investment, and the imbalance of urban and rural education resource allocation. [12] Due to the deep-rooted division and rule of urban and rural education, the unreasonable distribution mode of basic education resources hinders the balanced development of education, and the education in rural and pastoral areas still lags behind the city in general. Even in this new new urbanization state, with tons of rural students entering the urban, the child of the migrant workers still can't have the same education resources as the urban students because of the Household Registration System and the fact that urban students' education rights were put first, which makes "education for everyone" a luxury. The economic social development level of Inner Mongolia lags behind 
that of the eastern developed areas. The rural and pastoral areas, especially the poor counties in nation level and in autonomous region level, lag behind in its region,county or city, and the education resources it possess is rather little, which restricts the development of the local education. This situation is in urgent need to be improved through the integrated development of urban and rural education.

\subsection{With unclear responsibilities of governments at all levels and low level of decentralization of the public investment system, it is difficult for education to develop.}

The primary challenge the education investment system is facing is the responsibility of government investment is unclear. And because of that, the financial sharing mechanism is unclear. In the education market, the areas and scope of government independent investment, government leverage investment, guiding market investment and market leading investment are not clear, which leads to the risk and trend of government investment responsibility generalization under the guidance of promoting education equity. [13]China's current education investment system is a local government responsibility system under the unified coordination of the central government, which is characterized by the government leading. This means that the local government bears a more important responsibility in education investment and education resource allocation. At the same time, the level of the main body of cost bearing of compulsory education is too low. The compulsory education financial system of "provincial overall planning, county-based" makes the county-level governments became the main fundraiser, due to the constraints of the economic foundation of the grass-roots government, the current situation of social development and other factors, the financial funds in Inner Mongolia are still relatively concentrated in cities and towns, the resource interaction between urban and rural areas has not yet formed, the radiation belt action of urban education development on rural pastoral areas is insufficient, and the development of rural education is difficult to promote. The inconsistent responsibility and ability of education investment of grass-roots government leads to the imbalance of education resource allocation between urban and rural areas.

\section{3 "Education immigration" dilutes the development level of education}

Due to the rapid development of urbanization, the decrease of rural school-age population and the slow down of local government's "caring" to rural education, a large number of rural schools have been merged, and the resources of rural schools that have not been merged is 
increasingly dropping, which leads to the one-way "urban mobility" of rural students and excellent teachers. The result is the decline and even extinction of rural education. In this background, the educational immigration policy of "two oriented, two included" came into being. From the perspective of implementation effect, although the educational immigration policy integrates educational resources and maximizes the efficiency of educational resources. But in essence, it is through the supply of the system to carry out the institutional redistribution of the original uneven distribution of educational resources. Essentially, it is a remedial system design within the framework of the urban-rural dual education system, which lacks the foresight of the policy implementation effect [14], resulting in a new polarization of education and leads to the decline of rural education; immigrant students have to make a difficult choice between paid high-quality educational resources and declining rural education. The merger or decline of rural schools can only damage the educational interests of the most vulnerable groups in rural areas.

\subsection{The lagging behind practical professional interests and low sense of belonging of professional levels of rural teachers weaken the power of education development}

The primary reason for the unfair ratio of teachers in urban and rural areas lies in the fact that rural preschool teachers face great difficulties in obtaining their practical professional interests. Due to the location disadvantage, salary supply, development platform and other factors, the construction of rural compulsory education teachers is still relatively backward. [15] As the most dynamic and competitive factor in the development of education, teachers are faced with employment choice, employment environment, job development, promotion prospects and other practical interest factors. There are great differences in educational facilities and resources between urban and rural areas in Inner Mongolia, with backward teaching environment in rural areas, weak educational foundation, lack of incentive mechanism for teachers, it is difficult to attract teachers. High quality education resources are concentrated in the city, which provides teachers with more favorable professional interests and development platform, and can give teachers a good sense of professional belonging. Therefore, high quality teacher resources tend to flow to the city, resulting in the phenomenon that the supplement speed of rural teacher resources is far lower than that of the city, resulting in the imbalance in the number and quality of teachers between urban and rural areas. 


\section{Countermeasures and suggestions}

Fair development and quality improvement of education are two major themes of China's education development in the new era. In the process of promoting China's education modernization, education modernization in ethnic areas is not only the focus of development, but also the short board that needs to be patched urgently. [16] In the background of urban-rural integration, education in ethnic minority areas ushers in rare opportunities for development. Through the supervision and evaluation of Balanced Development of National Compulsory Education in Inner Mongolia Autonomous Region, the comprehensive coefficient of difference of primary school in 103 counties (cities and districts) is less than 0.65 , reaching the national standard, with the average value of primary school comprehensive coefficient of difference of 0.451 ; the comprehensive coefficient of difference of junior middle school in 103 counties (cities and districts) is less than 0.55 , reaching the national standard, with the average value of junior middle school comprehensive coefficient of difference of 0.301. [17] In the process of promoting education equity, the development of compulsory education in Inner Mongolia has made a historic leap forward, but there is still a lot of room for development to realize the high-quality balance, especially the unbalanced development of urban and rural education has become the main cause of the unbalanced development of education. The integration of urban and rural compulsory education is conducive to improving the resource sharing of urban and rural areas in the implementation process of compulsory education, and realizing the dynamic balance of distribution. Integration is not non-differentiation or homogenization. Rural education can learn from the concept of urban education, but should not be simply coping and imitating. On the premise of not separating urban education from rural education, according to the development characteristics and current situation of rural education, rural primary and secondary schools should be encouraged to develop their own advantages according to their own characteristics, narrow the gap between urban and rural areas, and integrate urban and rural education resources. The integration of urban and rural areas will promote the overall common development of urban and rural areas.

\subsection{Strengthen the top-level design and build a multi-governance community of urban and rural education led by the government}

In ethnic minority areas, the awareness of participation of multiple governance subjects is weak, and the government and provincial education management departments are more putting on a "one-man show" in the process of providing public education services, which strengthens the government's main body function and weakens the joint governance and 
collaborative participation of society and market. Government should change the concept of government management while coordinating and making education policies, fully respect the autonomy of rural schools, explore the establishment of education mode to adapt to the sustainable development of rural education, and encourage the linkage of urban and rural basic education collectivization. It is also necessary to activate the principal and teacher's participation consciousness of the school as an educational entity, which is not only limited to mechanical implementation, but also to enable them to jump out of the complicated logistics support and teacher-student safety system affairs, concentrate on running the school and studying, and pay attention to the aspirations of students and parents as the objects of educational service.

In the specific implementation process: first, give the rural school principals full autonomy and academic autonomy, but with strict quality control and process evaluation; second, create a good atmosphere of "respecting teachers and valuing education", give full play to the main role of rural teachers as the "soul of education", encourage rural teachers to innovate teaching methods, give care in life and work, and stimulate rural teachers' enthusiasm and also teachers' sense of professional belonging and lofty mission; third, in the selection and employment of rural school principals, we should strictly assess their moral cultivation and academic philosophy, and encourage them to carry out practical exploration of education reform; fourth, we should establish an assessment and evaluation system. Regularly organize the third-party quality control evaluation and supervision participated by the government, society and the representatives of parents' heads, and regularly feed back education opinions and suggestions, so as to mobilize the enthusiasm of all parties to participate.

\subsection{Break the system and mechanism barriers and promote the two-way flow of urban and rural education resources}

The concentration of urban high-quality education resources not only attracts high-quality students from rural areas, but also attracts many high-quality teachers. The trend of resource flow is one-way flow from rural to urban areas, which aggravates the impoverishment of rural education resources and the decline of education quality. Thus formed an essential inequality to the "vulnerable groups" who are forced to receive education in rural areas for they don't have the conditions to study in urban areas. The unfairness of education makes it difficult for a large part of rural groups to enjoy fair and quality education. With the improvement of people's living standards and the popularization and implementation of the compulsory education law, the fairness of educational opportunities has been basically realized, and people 
are looking forward to the fairness of high-quality educational opportunities. It is necessary to ensure that every child has the opportunity to enjoy high-quality educational resources at least in the stage of basic education. The key and difficult point lies in the fairness in the process and result of education, that is, to change from basic balance to high-quality balance, from resource allocation as the core to quality improvement as the core, from extension development to connotation development, from passive development relying on the government to independent development of schools. The premise of high quality equilibrium is equilibrium, and the core is high quality. First is to reform the financial sharing mechanism, polish and adjust different education funds output grades, and introduce social capital to alleviate the practical problems of the shortage of educational funds, backward teaching equipment and insufficient teachers in rural schools;[19] second is to focus on the long-term development of Education Driven Rural Revitalization. The central and provincial governments should further strengthen the financial transfer to the poverty-stricken areas of ethnic minorities and hold the bottom line; third is to explore the cooperation between urban and rural schools, and make the education resources in the cities to "Complementary advantages, learn from each other" [19]. Finally and most importantly, we should pay attention to the improvement of education quality, that is, the improvement of "soft power".

\subsection{Continue to implement the "rural teacher support plan", and make the preferential policies to be further extended to the areas with poor teacher resources.}

As a result of long-term neglect, rural schools have been in the plight of insufficient teachers, unstable team, unreasonable structure and more substitute teachers, which has become an important factor restricting the development of rural education. There is a big gap between urban and rural teachers in terms of economic income, promotion and living treatment. Compulsory education teachers in the county show a single upward flow into the county schools. The implementation of "rural teachers support plan" has improved the allocation of rural teachers' resources, steadily improved the level of education and teaching ability, guaranteed the reasonable treatment in all aspects according to law, and significantly enhanced the attractiveness of the profession. However, there are still some difficulties, such as lack of finance or insufficient investment in some areas, inadequate implementation of non explicit treatment such as housing provident fund, insurance and turnover dormitory, and ineffective implementation of two-way exchange system in counties. First of all, we should start with the construction of the teaching staff in the areas where the teacher resources are scarce, appropriately increase the proportion of rural teachers, attract excellent talents, 
implement the system of county management and school appointment and job rotation within the county, increase the salary of rural teachers, and increase the special allowance for teachers in the areas where the conditions are difficult. The more difficult the local condition is, the higher the special allowance of rural teachers will be, so that the salary of rural teachers will not be lower than or even higher than that of urban teachers. According to the degree of contribution and the spirit of dedication, we should give policy preference to the teachers who work in rural areas and have been engaged in rural education for more than a certain number of years. Secondly, it is necessary to establish a two-way flow mechanism of urban and rural teacher resources. Teachers in county and rural schools flow regularly in terms of quantity and quality, forming a flow state in which the city leads the township, the township helps the city, and urban and rural teachers develop and grow together. [20] Third, rural teachers' further study, joint training and directional training should be normalized, and rural teachers should be selected regularly and proportionally to go to famous universities for further study.

\subsection{Vigorously develop rural preschool education to solve the problems of rural children's "difficulty" and "too expensive" to enter the kindergarten.}

Preschool education is the starting point of one's education and lifelong learning, which is an important part of the national education system. Due to the influence of historical and practical factors, problems such as "unreasonable layout", "high tuition", "extreme lack of teachers" and "insufficient supporting infrastructure" have emerged in the development process of rural preschool education, which are the direct causes of the problems that are strongly reflected by the rural people _ _ " "difficult and expensive admission" . In Inner Mongolia, after the implementation of the three-phase preschool education action plan, the coverage rate of rural preschool education has greatly improved, but the layout of inclusive kindergartens in remote agricultural and pastoral areas still can not fully meet the needs of local residents, high-quality kindergartens are scarce, and professional preschool teachers are insufficient. To vigorously develop rural preschool education, we should accelerate the formulation of the "preschool education law", expand the coverage of governance funded preschool, guide social forces to hold more inclusive kindergartens, strengthen the docking and integration of urban and rural preschool education resources, give full play to the advantages of the radiation of urban high-quality preschool education resources and the linkage between urban and rural areas, and promote the construction of integrated rural preschool education supply network of district, county, township and village, which can activate the vitality and endogenous force of rural preschool education development.[21] 
Promote preschool education, especially in rural areas, from quantitative development to balanced development, to quality improvement, to characteristic development and innovative development.[22]

\subsection{Promote targeted poverty alleviation in education to prevent students from dropping out of school due to family difficulties}

President Xi Jinping once pointed out that "the poorer the place is, the poorer the education is, but the poorer the place is, the more education is needed, and the poorer the education is, the poorer the place is." [23] Education targeted poverty alleviation is the booster of "blocking the intergenerational transmission of poverty" and the catalyst of promoting social classes mobility. Ethnic minority areas are the main battlefields for poverty alleviation. Among the 14 contiguous poverty-stricken areas in China, 11 are distributed in ethnic minority areas. In 2016, the Ministry of education and other departments jointly issued the "13th five year plan for poverty alleviation", which pointed out: "to realize the full coverage of basic public services for the education of the poor people, such as the poverty card establishment, to guarantee the full funding of all education stages from enrollment to graduation, to ensure that children from poor families can go to school, and not to let a single student drop out of school due to family difficulties." However, in the deep poverty-stricken areas, the concept of education is backward, the self-sufficiency rate of education finance is low, and the strength of endogenous development is weak. We should increase the amount of education funds arranged by the central government, help the poverty-stricken areas fundamentally solve the problem of poverty, "make up the short board", accelerate the standardization of education public services, and use standardization to drive equalization. We should attach importance to the support for the disadvantaged groups in education, subsidize girls to go to school, increase the number of years of education for rural women, and teach them how to fish, so that they can have the ability to create a better life.

\subsection{Promoting education informationization and vigorously developing "Internet +" Education}

Educational informatization is a shortcut to give full play to the advantages of technical means and realize the sharing of high-quality educational resources in ethnic areas. It is a "shortcut" to break through the space restrictions and make minority students and Han students learn and grow together. It is an important measure to promote educational equity. We 
should vigorously promote the application of "Internet+education" in the compulsory education stage, and promote the public's support for policy implementation in the form of "Internet +". From the student point of view, through the "Internet+education" mode, we can get high-quality educational resources, break the traditional teaching mode of textbooks, desks and blackboards, and enjoy the rich teaching contents provided by the excellent teachers team through appropriate platforms and appropriate educational modes when rural compulsory education schools can't provide high quality service. "Internet+education" is undoubtedly the best way for rural compulsory education schools to provide quality services. The best way to obtain educational resources. At present, the plan of "Internet+education" is not very difficult to land, but the internet penetration rate in rural areas needs to be improved. The state is in the stage of vigorously supporting education, and "Internet+education" is an inevitable trend of development. We should popularize "Internet+education" and guide all roles involved in education to correctly understand, narrow the gap between urban and rural areas, and promote the integration process of compulsory education in urban and rural areas.[24]

\section{Conclusion}

Fairness in education, especially in the stage of compulsory education, is the most easily perceived fairness in every family, and it is also the most important way to improve people's sense of happiness and gain. The unbalanced development of urban and rural education has become an important manifestation of the main contradictions in the field of education in the new era. To implement the integration of urban and rural education in ethnic minority areas, we should adhere to the people-centered principle, vigorously promote educational equity, drive the overall prosperity and development of urban and rural areas, make the achievements of educational development more equitably benefit the people of all ethnic groups, effectively guarantee the basic right to education of the people of all ethnic groups in rural pastoral areas, let every child have a chance to go to school, and let the people of all ethnic groups enlightens the mind through education, so as to realize the value of life and the all-round development of human beings.

\section{References}

[1] Changzheng Zhang, Zhijian Jia, Huaizu Li. Empirical research on the degree of education equity in China: 1978-2004 -- Based on the calculation and analysis of Education Gini coefficient[J]. Educational research of Tsinghua University, 2006 (2): 10-14

[2] Baicai Sun. Measuring educational equality in the past 30 years of China's reform and opening up -- An Empirical Analysis Based on Education Gini coefficient [J]. Education 
research, 2009 (4): 12-18

[3] [11]Baicai Sun, Yang Zhang, Yunpeng Liu. Educational achievement and educational equity of Chinese ethnic populations: a comparison based on the data of the last three population censuses [J]. Ethnic studies, 2014 (3): 25-36 + 124

[4] [12]Dexin Hu. Regional comparative study on the degree of education equity between urban and rural areas in China [J]. Contemporary education science, 2017 (3): 14-18

[5] Wanming Zhang. Analysis of China's educational resource allocation and Policy Choice -Based on the calculation of Education Gini coefficient[J]. Journal of Renmin University of China, 2013, (04): 89-97

[6] Zhenhua Wu, Xuemin Zhang. An Empirical Study on education equity of rural residents in China -- Based on the calculation and decomposition of education Gini coefficient from 1988 to 2012 [J]. Education economic review, 2017 (3): 20-37

[7] Yuetang Chen, Zhixiang Lei. Differences and trends in the development of educational equity in China: a regional comparison based on Gini coefficient of Education [J]. JOURNAL OF HUNAN AGRICULTURAL UNIVERSITY (SOCIAL SCIENCE EDITION), 2019,20 (3): 90-96

[8] SHUJIE YAO.On the decomposition of Gini coefficients by population class and income source: a spreadsheet approach and application[J].Applied Economics,1999,31 (10): $: 1249-1267$.

[9] Hangkong Zhang, Feixia Ji. Empirical research on education equity in China: 1982-2010 -- Analysis Based on the decomposition of Education Gini coefficient [J]. Educational science, 2013,29 (6): 1-6

[10] Junsen Zhang,Tianyou Li.International Inequality and Convergence in Educational Attainment, 1960-1990[J].Review of Development Economics,2002,6 (3) :383-392.

[13] Wanpeng Zhang, Mengqi Li. Moving forward in hesitation -- exploring the way of education investment system with Chinese characteristics [J]. Education development research, 2020,40 (11): 1-7

[14] Hongqi Chu, Qian Zhao, et al. Educational reform in the process of urbanization [M]. Beijing: Educational Science Press, 2016:162-163

[15] Guangfei Wang, LINRONG Fu. The dilemma and Countermeasures of promoting the balanced development of compulsory education through the integration of urban and rural education $[\mathrm{J}]$. Rural economy, 2018 (03): 112-117

[16] Bater Chen. Accelerating the modernization of Ethnic Education [J]. Ethnic education in China, 2020 (1): 15

[17] The data comes from the website of Education Department of Inner Mongolia

Autonomous Region.

https://www.nmgov.edu.cn/hygq/yjta/zxta/202010/t20201021 59947.html

[18] Xiaoli Xu. Empirical research on the degree of education equity in China: 2004-2012 --

Based on the calculation and analysis of Gini coefficient of Education [J]. Education and teaching forum, 2018 (10): 211-213

[19] Compilation group. Development report of Chengdu Regional Education Alliance [M]. People's publishing house, 2015:62

[20] Fangting Qiu. Practical problems and Countermeasures of teacher flow in the integration of urban and rural education in County [J]. Education exploration, 2016 (2): 15-18

[21] Gengli Zhang. Practical difficulties and promotion strategies of Rural Preschool Education Collectivization Development from the perspective of urban rural integration [J]. Journal of educational science of Hunan Normal University. 2018 (03): 54-58

[22] Hongzhi Long, Huimin Yuan. Achievements, experiences and Reflections on the 
development of preschool education in ethnic minority areas in China in recent ten years [J]. Contemporary education and culture, 2021,13 (01): 109-116

[23] Xi Jinping. How should we do well in education [M]// Xi Jinping. Get rid of poverty. Fuzhou: Fujian people's publishing house, 1992:129.

[24] Lijuan Wang. Differences in educational attainment and new ideas of targeted poverty alleviation in Liangshan area: analysis of Gini coefficient based on the educational years of ethnic and Han students (2000-2015) [J]. Research on ethnic education, 2019,30 (02): 22-30 